\title{
Expert Discussion: Hypofractionated Radiation Therapy - Standard for All Indications?
}

\author{
Gerd Fastner $^{\mathrm{a}}$ David Krug ${ }^{\mathrm{b}}$ Icro Meattini ${ }^{\mathrm{c}, d}$ Günther Gruber ${ }^{\mathrm{e}, \mathrm{f}}$ \\ Philip Poortmans ${ }^{g, h}$ \\ ${ }^{a}$ Department of Radiotherapy and Radio-Oncology, Paracelsus Medical University, University Hospital Salzburg, \\ Landeskrankenhaus Salzburg, Salzburg, Austria; ${ }^{b}$ Department of Radiation Oncology, University Hospital Schleswig \\ Holstein, Kiel, Germany; 'Department of Experimental and Clinical Biomedical Sciences "M. Serio", University of \\ Florence, Florence, Italy; ${ }^{d}$ Radiation Oncology Unit, Oncology Department, Azienda Ospedaliero Universitaria \\ Careggi, Florence, Italy; ${ }^{\mathrm{e}}$ Institute of Radiotherapy, Klinik Hirslanden, Zurich, Switzerland; ${ }^{\mathrm{f}}$ University of Berne, \\ Berne, Switzerland; IIridium Netwerk, Wilrijk-Antwerp, Belgium; h University of Antwerp, Wilrijk-Antwerp, Belgium
}

\section{Fastner: In Your View, Are There Any Subgroups of Patients, Which Might Not Be Eligible to Be Irradiated by a Moderate Hypofractionated Treatment Concept after Breast-Conserving Surgery or Mastectomy?}

Krug: Level I evidence from randomized controlled trials and a Cochrane meta-analysis of these trials support moderate hypofractionation as the standard of care for whole-breast radiotherapy. It is important to point out that uncertainties regarding moderate hypofractionation for specific subgroups, such as very young patients, patients with connective tissue disorders or patients with neoadjuvant chemotherapy, do not result from signs of inferiority from the landmark trials but from the fact that some patient populations were not well represented. We now have additional data from newer trials, such as DBCG-HYPO [1], as well as population-based and institutional series [2-5], which overwhelmingly support moderate hypofractionation with similar or, in some endpoints, improved results regarding oncologic outcome and toxicity as compared to standard fractionation. Thus, I believe that there are no clear contra-indications to moderate hypofractionation.
Meattini: In my view, all subgroups of patients might be irradiated by a (at least) moderate hypofractionated treatment. The Ontario Clinical Oncology Group trial and UK START trial B, comparing moderate hypofractionation (40-42.5 Gy in 15-16 fractions) with 50 Gy in 25 fractions, showed comparable 5-year rates of local recurrence and improved acute normal tissue effects (NTE) $[6,7]$. Long-term results confirmed initial outcomes in terms of both efficacy and safety $[8,9]$. No specific subgroup of patients for whom hypofractionation led to a worse outcome in terms of neither efficacy nor NTE was identified. Moreover, several systematic reviews and meta-analyses on hypofractionation confirmed the effectiveness and safety of moderate hypofractionation as compared to 2-Gy daily fractionated schedules [10-12].

A single-center trial of postmastectomy radiation therapy (RT) on 810 women with primary T3 -4 tumors or $4+$ nodes randomized to 43.5 Gy in 15 fractions or 50 Gy in 25 fractions both to the chest wall and level 3-4 axillary nodal regions, demonstrating similar locoregional recurrence and no significant increase in late NTE at 5 years [13]. Overall, the only significant observed feature is the reduced severity of acute NTE in patients treated with moderate hypofractionation. In my opinion, 
and in line with the brand-new European Society for Radiotherapy and Oncology (ESTRO)-Advisory Committee in Radiation Oncology Practice (ACROP) consensus recommendations on patient selection and dose/fractionation for external beam RT in early breast cancer [14], moderate hypofractionated whole breast irradiation (WBI) should be offered regardless of age at breast cancer diagnosis, pathological tumor stage, breast cancer biology, surgical margins status, tumor bed boost, breast size, ductal carcinoma in situ (DCIS) of the breast, oncoplastic breast-conserving surgery, and use of systemic therapy.

Poortmans: There are absolutely no subgroups of patients that might not be eligible for moderately hypofractionated RT unless you (we) want to combine it with systemic therapy and aim at obtaining positive interaction like radiosensitisation by simultaneous/concomitant administration during a maximum of time.

I do realize that not all imageable subgroups, from a statistical point of view, were well represented in the studies. Therefore, and similar to many examples in surgery and in systemic therapy, application to the entire breast cancer population requires some intra- and extrapolation of the wealth of data that is available overall $[10,11,14]$. Notwithstanding this plenitude of evidence supporting the use of moderate hypofractionation for breast cancer, its introduction in daily clinical routine remains cumbersome in many places of the world $[12,15]$. Apart from improved dissemination of evidence-based recommendations to improve the level of awareness among clinicians, involvement of the patients' organizations and addressing inappropriate and counterproductive reimbursement systems (e.g., payment per fraction) should be envisaged [16, 17]. Finally, whereas I do support participation to trials addressing fractionation questions in very specific subgroups, including after breast reconstruction and for re-irradiation, I strongly support routine use of moderate hypofractionation in these cases as namely the 40 Gy in 15 fractions over 3 weeks schedule is demonstrated to be more gentle concerning normal tissues effects compared to the "historical" schedule of 50 Gy in 25 fractions $[9,12,14]$.

Gruber: There is convincing evidence that moderate hypofractionation demonstrates equivalent cosmesis and outcome. The vast majority of patients were treated after breast-conserving surgery without regional nodal irradiation and chemotherapy. However, these patients were eligible and included, for example, in the START trials [18]. So, if you accept these trials as "proof of principle" to apply a biologically equivalent dose, there is no subgroup of patients where moderate hypofractionated RT cannot be given. This is also supported by randomized studies of Wang et al. [13] in patients with mastectomy or in DCIS, like the Danish HYPO trial [1] or the DCIS BIG
3-07 trial [19]. This might be even true for breast reconstruction according to retrospective data [20]. For local irradiation, the 3-week regimen is my first choice regardless of patient subgroup, except for breast reconstruction, where I still prefer "standard" single doses. To my knowledge, the interplay of hypofractionation and an eventual bolus is not fully clear. Unfortunately, it will take some time to gather data from randomized trials, such as FABREC [21] or RT CHARM [22]. For planned trials such as NEORAD [23], hypofractionation in breast reconstruction is allowed.

\section{Fastner: In Your Opinion, Is There Enough Evidence to Recommend Regional Lymph Node Irradiation with Moderate Hypofractionation as First Treatment of Choice?}

Krug: Data from a randomized controlled trial from China [13], a subgroup from the START trials [8], as well as several cohort studies [24-27] support moderate hypofractionation as a reasonable alternative to conventional fractionation for patients with an indication for regional nodal irradiation. However, several prospective randomized controlled trials studying specific aspects, such as lymphedema and reconstruction complications, are still ongoing. In my opinion, moderate hypofractionation will most likely replace conventional fractionation as the standard of care for patients requiring regional nodal irradiation in the years to come, but we are not there yet.

Meattini: Although a minority of patients enrolled in the START trials using moderate hypofractionation received nodal irradiation, there have been no concerns in terms of both safety and cancer control [8]. Moreover, all patients treated in the Beijing trial received lymph node irradiation, reporting equivalent late NTE rates [13]. The UK IMPORT HIGH trial [28], a randomized phase 3 trial testing dose escalated simultaneous integrated boost (SIB) against sequential boost using intensity-modulated RT and image-guided RT for early-stage breast cancer with high local relapse risk, includes a proportion of patients receiving moderately hypofractionated regional lymph node irradiation and showed equivalent efficacy and safety profiles. Indeed, in my opinion, moderate hypofractionated regional lymph node irradiation, UK and the Netherlands' standard of care for over a decade, should be widely adopted across Countries.

Poortmans: Absolutely yes. In fact, my reply to the first question could be nearly completely copied here. I base this also on broad personal experience, with hypofractionation (42.56 Gy in 16 fractions) being introduced broadly in the Netherlands in 2009, after completion of the young boost trial in 2011 for all patient's ages and all indications. 
Gruber: The history of treating regional lymph nodes, especially the supraclavicular fossa, created a lot of reluctance for hypofractionation, as some old trials have shown a relatively high risk for brachial plexopathy [29]. As the latency from RT end to onset of symptoms could be as long as 30 years [29], several colleagues demand for longterm follow-up before they are willing to change their practice. The risk of plexopathy for modern hypofractionated radiotherapy schedules and modern treatment planning is minimal. Isoeffective schedules will behave isoeffectively on the plexus. Keeping EQD2 up to 50 Gy seems to be very safe. In the current S3 guidelines [30], moderate hypofractionation is an option, but the 5-week treatment is still preferred for treating lymph nodes. Several breast centers in Switzerland as ours are certified by the DKG (German cancer society) following the $\mathrm{S} 3$ guidelines as their recommendation. Personally, if there is a clear wish for a 3-week regimen, I have no problems to offer it to the patient.

\section{Fastner: What Are Your Arguments in Favor or against a Simultaneously Integrated Tumor Bed Boost as Part of Hypofractionated WBI for 3 Weeks?}

Krug: Currently, we lack evidence from large randomized controlled trials comparing sequential boost administration to SIB in the context of moderate hypofractionation. A multitude of prospective single-arm trials have demonstrated favorable results and data from two phase III trials of SIB with conventional fractionation have been recently published [31-34]. However, similar to the situation for regional nodal irradiation, this is not sufficient to change the standard of care. When discussing this with patients, I would refer to the shortening in overall treatment time and improved dose homogeneity on the positive side, but on the other side allude to uncertainties in long-term outcomes in the absence of randomized controlled trials with sufficient patient numbers.

Meattini: During the last few years, a method of dose escalation to the tumor bed by a SIB was investigated [35]. There is a strong rationale in favor of a SIB as part of postoperative WBI, although a level 1 evidence for a 3-week course does still not exist. The chance to obtain a dose escalation at the tumor bed level without prolonging treatment duration and potentially increasing the sensitivity of breast cancer cells, augmenting the dose per fraction and decreasing the overall treatment course time, is highly appealing, especially in terms of patient compliance. Conversely, the potential unfavorable effect in terms of late NTE rates impacting on cosmetic outcome is known and still represent the focus of ongoing studies [36]. We have also to take into account that these highrisk patients are commonly candidates to receiving sys- temic treatments able to worsen the overall safety profile of treatments. Finally, we have to consider that plans including a SIB are undoubtedly more complex as compared to sequential boost ones and should foresee interfractions controls.

The recently reported outcomes of the IMPORT HIGH trial [28] at the ESTRO annual meeting 2021, testing dose-escalated SIB against sequential boost $(36 \mathrm{~Gy} / 15$ fractions to whole breast, $40 \mathrm{~Gy}$ to partial breast, 48 or 53 Gy in 15 fractions of SIB), showed a low ipsilateral breast tumor recurrence event incidence whether the boost was delivered sequentially or simultaneously with the $95 \%$ CI excluding the 5-year rate originally predicted for the control group. Rates of 5-year moderate/marked adverse events were also low.

In my opinion, this study added further arguments in favor of SIB as a safe treatment with reduced patient visits without any need for further escalation of boost dose. Although the routine use of SIB during hypofractionated WBI schedules is not recommended, I do believe that brand-new data represented a step more towards the framework of a breast cancer postoperative treatment of a maximum of 15 fractions depending on the risk cohort.

Poortmans: First of all, most consider a SIB as being a treatment that maintains a constant number of fractions compared to when no boost is given, with a (most often) daily additional dose to the boost target volume. However, a SIB might also maintain the total number of fractions (first series + boost) constant or only moderately reduced, as was broadly introduced in the Netherlands in 2005 and used as preferred scheme in, for example, the Young Boost Trial (BOOG 2004-01) with a fraction size of 1.81 Gy to the breast \pm regional lymph nodes and 2.30 to the primary tumor bed for a total of 28 fractions (reduction of 5 fractions compared to $25+$ 8 before) in the standard arm [37]. With the introduction of moderate hypofractionation in the Netherlands in 2009, the SIB fraction size at the primary tumor bed was maintained at $2.66 \mathrm{~Gy}$, while lowering the dose to the volumes outside of the boost to $2.17 \mathrm{~Gy}$, thereby using the same number of fractions as with a sequential boost $(16+5=21)$. In favor of all types of SIB are the clear dosimetric advantages and the facilitated setup procedures. In an in-depth analysis of 124 patients, hypofractionation had a favorable effect on quality of life and (borderline) on cosmetic outcomes, while oncoplastic surgery had an adverse effect and the boost technique (simultaneous integrated vs. sequential) had no effect on both endpoints [38].

Against the SIB, notably when the total number of fractions is reduced by delivering higher doses to the tumor bed, is that we did not have much data. However, very recently (August 2021), the 5-year primary results of the IMPORT HIGH trial (CRUK/06/003) were presented 
at ESTRO 2021 in Madrid after a median follow-up of 74 months [28]. These confirm that local recurrence rates are low, even in this population of high-risk breast cancer patients, independent from the type of boost delivery (sequentially or simultaneously), and without further improvement with an increased SIB dose. Moreover, adverse effect rates are low.

Finally, and very importantly, we should not only discuss "how" to deliver a boost, but also "when" to deliver a boost. Since local recurrence rates dropped impressively over the past 3 decades, and delivery of a boost has a negative impact on the cosmetic outcomes, a boost should only be given to patients at high risk for local recurrences [39-43]. Unfortunately, similar to the application of hypofractionation in clinical practice, also here many colleagues remain reluctant to abandon the boost, even in low-risk patients, with boost delivery in the framework of breast-conserving therapy varying from about 15 to $25 \%$ in countries like Denmark and the UK to virtually $100 \%$ in many other countries $[16,44]$.

Gruber: One obvious benefit for the patient is a further reduction of fractions and overall treatment time. Giving the boost simultaneously by increasing the single dose of about 0.5 Gy to the tumor bed, leading to $3 \mathrm{~Gy}$ in the tumor bed and $2.5 \mathrm{~Gy}$ for the whole breast, shortens the radiotherapy further to about 3 weeks instead of 4-4.5 weeks. There is convincing evidence that dose homogeneity will be improved by SIB technique. To my knowledge, acute toxicity is quite comparable; however, in the MINT trial, there was a higher incidence of radiation dermatitis grade $2-3$ in patients treated with intensity-modulated radiotherapy-SIB at the end of treatment [34]. Personally, I want to see more data, especially on late toxicity, for example, from the RTOG1005 [45] and HYPOSIB [46] trials. One practical aspect, which is however seldom the case: there are patients in which I abandon a boost RT due to more pronounced acute toxicity after whole breast $\mathrm{RT}$. This is not an option if the boost is given simultaneously.

\section{Fastner: As a Member of a National Committee for Preparing Updated Treatment Guidelines for Breast Cancer, What Kind of Emphasis Would You Put on Ultra-Hypofractionated WBI Scheduled for Only 5 Days?}

Krug: In Germany, we have included ultra-hypofractionation as an additional option besides moderate hypofractionation, which represents the standard of care, and conventional fractionation $[47,48]$. There are several specific clinical scenarios where I think that ultra-hypofractionation is a valuable addition to the radiation oncology toolbox. Personally, I would consider ultra-hypofraction- ation in elderly patients not suited for radiotherapy omission or partial breast irradiation after breast-conserving surgery due to risk factors. Furthermore, I would consider ultra-hypofractionation in patients suffering from mobility impairment or in patients who rank the shortest possible treatment time as a top priority. In light of the COVID-19 pandemic, ultra-hypofractionation has been adopted in many countries as a means to reduce treatment appointments and, hence, the risk of associated virus transmission for patients and radiation oncology professionals likewise. Aside from the specific circumstances regarding management of breast cancer during the current pandemic, I would counsel patients regarding a possible increase in the risk of late normal tissue complications, although absolute differences between the standard arms and the lower-dose ultra-hypofractionated treatment arms in the FAST and FAST-Forward trials were fairly small.

From my point of view, further data are needed to establish ultra-hypofractionation as the standard of care.

Meattini: At a median follow-up of 6 years, the FASTForward phase 3 trial on 4,096 patients showed that 26 Gy in 5 daily fractions WBI leads to noninferior local control rates (HR vs. 40 Gy of 0.67 [95\% CI 0.38 to 1.16] in favor of $26 \mathrm{~Gy}$ ) and similar NTE profile as compared to $40 \mathrm{~Gy}$ in 15 fractions over 3 weeks [49]. Late NTE were similar for 26 Gy (HR 1.12, 95\% CI 0.94 to 1.34 ; $p$ $=0.20$ ), while breast induration outside the tumor bed was the only statistically significant worse NTE result, with extremely low event rates (reported moderate/ marked events rate of $1.9 \%$ in $26 \mathrm{~Gy}$ ). In my opinion, this study represents one of the most important practice-changing trials in radiation oncology of the last decade and an unvaluable achievement for patients affected by breast cancer. Further studies and longer followup will certainly add robust data on the 5-fraction schedule. However, in my view, 26 Gy in 5 fractions WBI can be already safely offered as standard of care for most of our patients [14]. Of course, the current low rates of NTE will increase over time, but these will increase in all groups of the trial, as it has been demonstrated by the long-term results of both the START B and FAST trials, where the HR for late NTE remained remarkedly similar both at 5 and 10 years $[9,37]$. In addition, as part of a scientific community, we should have the duty to translate new evidence more quickly than in the past into our routine daily practice.

Poortmans: After the publication of the results of the FAST-Forward trial, with a median follow-up of 71.5 months, ultra-hypofractionated RT clearly became the new standard for breast only and for thoracic wall only [49]. Moreover, it is an option for chest wall after breast reconstruction. While the COVID-induced "pandemisery" facilitated rapid introduction in clinical trials, it 
should by no means be considered as a "crisis-schedule" [50]. I also expect that ultra-hypofractionation will probably become the new standard for locoregional RT in 2-3 years, after the presentation of the FAST-Forward nodal sub-study.

It is clear that, similar to the adaptation of moderate hypofractionation, considerable reluctance exists regarding the clinical introduction of ultra-hypofractionation for a broad subgroup of breast cancer patients [14, 16]. Indeed, similar to the moderate hypofractionation studies in breast and prostate cancer, small differences in fractionation can have a measurable impact on endpoints, as seen in the 27 Gy in 5 fractions treatment arm, which was, therefore, preliminary closed for accrual in the nodal sub-study. Importantly, with $40 \mathrm{~Gy}$ in 15 fractions being gentler for NTE than the "historic" 50 Gy in 25 fractions, we see that 26 Gy in 5 fractions is iso-effective for NTE with the 40 Gy in 15 fractions, while the 27 Gy in 5 fractions approximates the side effects seen with the 50 Gy in 25 fractions schedule, which is still adhered to by so many colleagues worldwide. Large trials, including the EORTC "boost" trial and the young boost trial, clearly demonstrate that the difference in development of fibrosis and the impact on cosmetic outcome with a (higher) boost dose is seen after 3-5 years and that, importantly, thereafter only little changes in frequency and severity of side effects occur $[42,43,51,52]$. The development of fibrosis at longer follow-up is rather a continuous process associated with WBI and thereby related to differential aging of the irradiated versus the nonirradiated breast, as demonstrated in the EORTC "boost" trial [53]. Therefore, a follow-up of 5 years, being in fact even rather 6 years for the FAST-Forward trial, can safely be accepted as sufficient evidence for long-term evolution of these endpoints. Quite particularly, highly inaccurate estimations from bar charts taken from the published appendices to the FAST-Forward paper, combined with a flawed methodology to perform a so-called re-analysis of the published data, have been used to unjustifiably criticize the results and to advise against clinical application of ultra-hypofractionation [48]. A fact is that the prevalence of moderate/marked late effects at 5 years was low in all schedules in FAST-Forward, the most prevalent being breast shrinkage as assessed by clinicians in only $5.5 \%$ of patients after $40 \mathrm{~Gy}$ in 15 fractions compared to $6.8 \%$ of patients after $26 \mathrm{~Gy}$ in 5 fractions. Finally, of course further cohort/registration evaluations are highly recommended. What about further randomized trials? To my opinion, we need the little money we receive for pure academic radiation oncology trials to be used for other research!

Gruber: The FAST Forward [49] schedule of 5 fractions of 5.2 Gy single dose is an option, but not a preferred one, and only for patients who are aware that side effects might get worse. As co-chair of the EXPERT trial [54], which is an ongoing RT trial of whole-breast RT in "lowrisk" patients worldwide, we have asked the local study chairs after the publication of FAST Forward, if the trial would change their current practice, which was actually not the case for most of them. On the other hand, two out of three Irish centers have rejected their foreseen participation due to their preference for ultra-hypofractionation.

The essential question: Is it too fast forward? What "frightens" a little bit: there was a third arm in the trial with 5 fractions of $5.4 \mathrm{~Gy}$. The increase of the single dose by only 0.2 Gy has led to a significantly worse toxicity profile, which points out that treatment planning is key.

Furthermore, most colleagues argue that follow-up is too short to judge about long-term toxicity. The authors of FAST Forward state in the Discussion of their paper that "although normal tissue effects continue to accumulate beyond 5 years, there is little evidence that relative differences between test and control groups change very little over time." As an example, they mentioned "breast shrinkage" in the START-B trial increasing from $11.4 \%$ at 5 years to $26.2 \%$ at 10 years, but with a "stable" hazard ratio of 0.83 at 5 years and 0.80 at 10 years between the two treatment arms. Looking at 5-year clinician-assessed "breast induration outside tumor bed" (online suppl. Table A2 of FAST Forward), ultra-hypofractionation was significantly worse, but absolute numbers are low. The interesting point: the hazard ratio is 19 (!), so an increase by longer follow-up can get much more pronounced to the disadvantage of ultra-hypofractionation. An important and comprehensive analysis by Krug et al. [48] showed significant differences in favor of the standard arm for induration, telangiectasia, and edema as well as for the sum of all NTE. Relative risks of the individual observations only reached significance after longer follow-up, suggesting that clinically relevant disadvantages may become apparent by time. By now, I treat patients quite seldom with ultra-hypofractionation.

\section{Conflict of Interest Statement}

Gerd Fastner: Lecture honoraria from Roche, outside of the submitted work.

David Krug: honoraria from Merck Sharp \& Dome, European School of Oncology and European Society for Medical Oncology, outside of the submitted work.

Icro Meattini: Advisory boards supported by Eli Lilly, Novartis, Istituto Gentili, Roche, Pfizer, Ipsen, and Pierre Fabre.

Philip Poortmans: Function as medical advisor of Sordina IORT Technologies spa, not related to the submitted work.

Günther Gruber: No conflict of interest to declare. 


\section{Chair}

\section{Prof. Gerd Fastner}

Department of Radiotherapy and Radio-Oncology

Paracelsus Medical University

University Hospital Salzburg, Landeskrankenhaus Salzburg

Müllner Hauptstraße 48

AT-5020 Salzburg (Austria)

g.fastner@salk.at

\section{Participants}

\section{Dr. David Krug}

Department of Radiation Oncology

University Hospital Schleswig-Holstein

Campus Kiel

Arnold-Heller-Straße 3, Haus L

DE-24105 Kiel (Germany)

david.krug@uksh.de
Prof. Icro Meattini

Department of Experimental and Clinical Biomedical Sciences "M. Serio"

University of Florence

Viale Morgagni 50

IT-50134 Florence (Italy)

icro.meattini@unifi.it

\section{Prof. Philip Poortmans}

Faculty of Medicine and Health Sciences

University of Antwerp

Campus Drie Eiken, Building S.

Universiteitsplein 1

BE-2610 Wilrijk-Antwerp (Belgium)

philip.poortmans@telenet.be

\section{Dr. Günther Gruber}

Institute of Radiotherapy

Klinik Hirslanden

Witellikerstraße 40

CH-8032 Zürich (Switzerland)

Guenther.Gruber@hirslanden.ch

\section{References}

1 Offersen BV, Alsner J, Nielsen HM, Jakobsen EH, Nielsen MH, Krause M, et al.; Danish Breast Cancer Group Radiation Therapy Committee. Hypofractionated versus Standard Fractionated Radiotherapy in Patients with Early Breast Cancer or Ductal Carcinoma in situ in a Randomized Phase III Trial: the DBCG HYPO Trial. J Clin Oncol. 2020 Nov; 38(31):3615-25.

2 Purswani JM, Oh C, Jaros B, Sandigursky S, Xiao J, Gerber NK. Breast Conservation in Women with Autoimmune Disease: The Role of Active Autoimmune Disease and Hypofractionation on Acute and Late Toxicity in a Case-Controlled Series. Int J Radiat Oncol Biol Phys. 2021 Jul;110(3):783-91.

3 Rock K, Ng S, Murray L, Su J, Fyles A, Koch CA. Local control in young women with early-stage breast cancer treated with hypofractionated whole breast irradiation. Breast. 2018 Oct;41:89-92.

4 Shaikh F, Chew J, Hochman T, Purswani J, Maisonet O, Peat E, et al. Hypofractionated Whole-Breast Irradiation in Women Less Than 50 Years Old Treated on 4 Prospective Protocols. Int J Radiat Oncol Biol Phys. 2018 Aug;101(5):1159-67.

5 Yoon SM, Chu FI, Ruan D, Steinberg ML, Raldow A, Lee P. Assessment of Toxic Effects Associated With Dose-Fractionated Radiotherapy Among Patients With Cancer and Comorbid Collagen Vascular Disease. JAMA Netw Open. 2021 Feb;4(2):e2034074.

6 Whelan T, MacKenzie R, Julian J, Levine M, Shelley W, Grimard L, et al. Randomized trial of breast irradiation schedules after lumpectomy for women with lymph node-negative breast cancer. J Natl Cancer Inst. 2002 Aug;94(15):1143-50.
7 Bentzen SM, Agrawal RK, Aird EG, Barrett JM, Barrett-Lee PJ, Bentzen SM, et al.; START Trialists' Group. The UK Standardisation of Breast Radiotherapy (START) Trial B of radiotherapy hypofractionation for treatment of early breast cancer: a randomised trial. Lancet. 2008 Mar;371(9618):1098-107.

8 Haviland JS, Mannino M, Griffin C, Porta N, Sydenham M, Bliss JM, et al.; START Trialists' Group. Late normal tissue effects in the arm and shoulder following lymphatic radiotherapy: Results from the UK START (Standardisation of Breast Radiotherapy) trials. Radiother Oncol. 2018 Jan;126(1):155-62.

9 Whelan TJ, Pignol JP, Levine MN, Julian JA, MacKenzie R, Parpia S, et al. Long-term results of hypofractionated radiation therapy for breast cancer. N Engl J Med. 2010 Feb; 362(6):513-20.

10 Andrade TR, Fonseca MC, Segreto HR, Segreto RA, Martella E, Nazário AC. Meta-analysis of long-term efficacy and safety of hypofractionated radiotherapy in the treatment of early breast cancer. Breast. 2019 Dec;48:24-31.

11 Hickey BE, James ML, Lehman M, Hider PN, Jeffery M, Francis DP, et al. Fraction size in radiation therapy for breast conservation in early breast cancer. Cochrane Database Syst Rev. 2016 Jul;7:CD003860.

12 Marta GN, Coles C, Kaidar-Person O, Meattini I, Hijal T, Zissiadis Y, et al. The use of moderately hypofractionated post-operative radiation therapy for breast cancer in clinical practice: A critical review. Crit Rev Oncol Hematol. 2020 Dec;156:103090.

13 Wang SL, Fang H, Song YW, Wang WH, Hu C, Liu YP, et al. Hypofractionated versus conventional fractionated postmastectomy radiotherapy for patients with high-risk breast cancer: a randomised, non-inferiority, openlabel, phase 3 trial. Lancet Oncol. 2019 Mar; 20(3):352-60.
14 Meattini IB, Becherini C, Boersma L, KaidarPerson O, Nader Marta G, Montero A, et al. European Society for Radiotherapy and Oncology Advisory Committee in Radiation Oncology Practice consensus recommendations on patient selection and dose and fractionation for external beam radiation therapy in early breast cancer. Lancet Oncol. 2022 Jan; 23.e21-e31.

15 Ratosa I, Chirilă ME, Steinacher M, Kozma E, Vojtíšek R, Franco P, et al. Hypofractionated radiation therapy for breast cancer: preferences amongst radiation oncologists in Europe - Results from an international survey. Radiother Oncol. 2021 Feb;155:17-26.

16 Cardoso F, MacNeill F, Penault-Llorca F, Eniu A, Sardanelli F, Nordström EB, et al. Why is appropriate healthcare inaccessible for many European breast cancer patients? - The EBCC 12 manifesto. Breast. 2021 Feb;55:128-35.

17 Marta GN, Ramiah D, Kaidar-Person O, Kirby A, Coles C, Jagsi R, et al. The Financial Impact on Reimbursement of Moderately Hypofractionated Postoperative Radiation Therapy for Breast Cancer: An International Consortium Report. Clin Oncol (R Coll Radiol). 2021 May;33(5):322-30.

18 Haviland JS, Owen JR, Dewar JA, Agrawal RK, Barrett J, Barrett-Lee PJ, et al.; START Trialists' Group. The UK Standardisation of Breast Radiotherapy (START) trials of radiotherapy hypofractionation for treatment of early breast cancer: 10-year follow-up results of two randomised controlled trials. Lancet Oncol. 2013 Oct;14(11):1086-94. 
19 Chua BH, Link E, Kunkler I, Olivotto I, Westenberg $\mathrm{AH}$, Whelan $\mathrm{T}$, et al; Breast International Group (BIG)-aisbl, Trans Tasman Radiation Oncology Group, Scottish Cancer Trials Breast Group, Canadian Cancer Trials Group, European Organization for Research and Treatment of Cancer, International Breast Cancer Study Group. Abstract GS2-04: A randomized phase III study of radiation doses and fractionation schedules in non-low risk ductal carcinoma in situ (DCIS) of the breast (BIG 3-07/TROG 07.01). Cancer Res. 2021 Feb;81(4S):GS2-04. doi: 10.1158/15387445.SABCS20-GS2-04.

20 Kim DY, Park E, Heo CY, Jin US, Kim EK, Han W, et al. Influence of Hypofractionated versus Conventional Fractionated Postmastectomy Radiotherapy in Breast Cancer Patients with Reconstruction. Int J Radiat Oncol Biol Phys. 2022 Feb;112:445-456.

21 Study of Radiation Fractionation on Patient Outcomes After Breast REConstruction (FABREC) for Invasive Breast Carcinoma. Available from: www.clinicaltrials.gov/ct2/ show/NCT03422003.

22 RT CHARM: Phase III Randomized Trial of Hypofractionated Post Mastectomy Radiation with Breast Reconstruction. Available from: www.clinicaltrials.gov/ct2/show/ NCT03414970

23 Neoadjuvant Chemotherapy Followed by Preoperative Radiotherapy in High-risk Breast Cancer: a Prospective, International Randomised Multicentre-phase III Trial. Available from: www.clinicaltrials.gov/ct2/ show/NCT04261244

24 Badiyan SN, Shah C, Arthur D, Khan AJ, Freedman G, Poppe MM, et al. Hypofractionated regional nodal irradiation for breast cancer: examining the data and potential for future studies. Radiother Oncol. 2014 Jan; 110(1):39-44.

25 Bellefqih S, Elmajjaoui S, Aarab J, Khalil J, Afif M, Lachgar A, et al. Hypofractionated Regional Nodal Irradiation for Women with Node-Positive Breast Cancer. Int J Radiat Oncol Biol Phys. 2017 Mar;97(3):563-70.

26 Koulis TA, Nichol AM, Truong PT, Speers C, Gondara L, Tyldesley S, et al. Hypofractionated Adjuvant Radiation Therapy Is Effective for Patients with Lymph Node-Positive Breast Cancer: A Population-Based Analysis. Int J RadiatOncolBiolPhys.2020Dec;108(5):1150-

27 Poppe MM, Yehia ZA, Baker C, Goyal S, Toppmeyer D, Kirstein L, et al. 5-Year Update of a Multi-Institution, Prospective Phase 2 Hypofractionated Postmastectomy Radiation Therapy Trial. Int J Radiat Oncol Biol Phys. 2020 Jul;107(4):694-700.

28 Coles CH, Haviland JS, Kirby AM, Bhattacharya I, Brunt AM, Chan C, et al. OC-0291 IMPORT HIGH trial: dose escalated simultaneous integrated boost radiotherapy in early breast cancer. Radiother Oncol. 2021; 161:S197-9.

29 Johansson S, Svensson H, Larsson LG, Denekamp J. Brachial plexopathy after postoperative radiotherapy of breast cancer patients - a long-term follow-up. Acta Oncol. 2000;39(3):373-82
30 Interdisziplinäre S3-Leitlinie für die Früherkennung, Diagnostik, Therapie und Nachsorge des Mammakarzinoms Kurzversion 4.3 - Juni 2021. Available from: www.awmf.org/ uploads/tx_szleitlinien/032-045OLk_S3_ Mammakarzinom_2021-07_1.pdf.

31 Choi KH, Ahn SJ, Jeong JU, Yu M, Kim JH, Jeong BK, et al. Postoperative radiotherapy with intensity-modulated radiation therapy versus 3-dimensional conformal radiotherapy in early breast cancer: A randomized clinical trial of KROG 15-03. Radiother Oncol. 2021 Jan;154:179-86.

32 Forster T, Hommertgen A, Häfner MF, Arians N, König L, Harrabi SB, et al. Quality of life after simultaneously integrated boost with intensity-modulated versus conventional radiotherapy with sequential boost for adjuvant treatment of breast cancer: 2-year results of the multicenter randomized IMRT-MC2 trial. Radiother Oncol. 2021 Oct;163:165-76.

33 Hörner-Rieber J, Forster T, Hommertgen A, Haefner MF, Arians N, König L, et al. Intensity Modulated Radiation Therapy (IMRT) With Simultaneously Integrated Boost Shortens Treatment Time and Is Noninferior to Conventional Radiation Therapy Followed by Sequential Boost in Adjuvant Breast Cancer Treatment: Results of a Large Randomized Phase III Trial (IMRT-MC2 Trial). Int J Radiat Oncol Biol Phys. 2021 Apr;109(5):131124

34 Krug D, Köder C, Häfner MF, Arians N, Harrabi SB, Koerber SA, et al. Acute toxicity of normofractionated intensity modulated radiotherapy with simultaneous integrated boost compared to three-dimensional conformal radiotherapy with sequential boost in the adjuvant treatment of breast cancer. Radiat Oncol. 2020 Oct;15(1):235.

35 Freedman GM, Anderson PR, Goldstein LJ, Ma CM, Li J, Swaby RF, et al. Four-week course of radiation for breast cancer using hypofractionated intensity modulated radiation therapy with an incorporated boost. Int J Radiat Oncol Biol Phys. 2007 Jun;68(2):347-53.

36 Sedlmayer F, Sautter-Bihl ML, Budach W, Dunst J, Feyer P, Fietkau R, et al.; Breast Cancer Expert Panel of the German Society of Radiation Oncology (DEGRO). Is the simultaneously integrated boost (SIB) technique for early breast cancer ready to be adopted for routine adjuvant radiotherapy? Statement of the German and the Austrian Societies of Radiooncology (DEGRO/ÖGRO). Strahlenther Onkol. 2013 Mar;189(3):193-6.

37 van Mourik AM, Elkhuizen PH, Minkema D, Duppen JC, van Vliet-Vroegindeweij C; Dutch Young Boost Study Group. Multiinstitutional study on target volume delineation variation in breast radiotherapy in the presence of guidelines. Radiother Oncol. 2010 Mar;94(3):286-91.

38 Lansu JT, Essers M, Voogd AC, Luiten EJ, Buijs C, Groenendaal N, et al. The influence of simultaneous integrated boost, hypofractionation and oncoplastic surgery on cosmetic outcome and PROMs after breast conserving therapy. Eur J Surg Oncol. 2015 Oct; 41(10):1411-6.

39 Poortmans PM, Arenas M, Livi L. Over-irradiation. Breast. 2017 Feb;31:295-302.
40 Bosma SC, Hoogstraat M, van Werkhoven E, de Maaker M, van der Leij F, Elkhuizen $\mathrm{PH}$, et al.; Young Boost Trial research group. A case-control study to identify molecular risk factors for local recurrence in young breast cancer patients. Radiother Oncol. 2021 Mar;156:127-35.

41 Kayali M, Jaoude JA, Ramia P, Assi H, Geara F, Poortmans P, et al. Post-lumpectomy radiation therapy boost in breast cancer patients: evidence revisited. Ecancermedicalscience. 2021 Mar;15:1194

42 Brouwers PJ, van Werkhoven E, Bartelink $\mathrm{H}$, Fourquet A, Lemanski C, van Loon J, et al.; Young Boost Trial research group. Predictors for poor cosmetic outcome in patients with early stage breast cancer treated with breast conserving therapy: results of the Young boost trial Radiother Oncol. 2018 Sep;128(3):434-41.

43 Bartelink $\mathrm{H}$, Maingon $\mathrm{P}$, Poortmans $\mathrm{P}$, Weltens C, Fourquet A, Jager J, et al.; European Organisation for Research and Treatment of Cancer Radiation Oncology and Breast Cancer Groups. Whole-breast irradiation with or without a boost for patients treated with breast-conserving surgery for early breast cancer: 20-year follow-up of a randomised phase 3 trial. Lancet Oncol. 2015 Jan;16(1):47-56.

44 Schreuder K, Maduro JH, Spronk PE, Bijker N, Poortmans PM, van Dalen T, et al. Variation in the Use of Boost Irradiation in BreastConserving Therapy in the Netherlands: The Effect of a National Guideline and Cofounding Factors. Clin Oncol (R Coll Radiol). 2019 Apr;31(4):250-9.

45 A Phase III Trial of Accelerated Whole Breast Irradiation with Hypofractionation Plus Concurrent Boost Versus Standard Whole Breast Irradiation Plus Sequential Boost for Early-Stage Breast Cancer. Available from: www.clinicaltrials.gov/ct $2 /$ show/ NCT01349322.

46 Adjuvant Radiotherapy After Breast-conserving Surgery in Early Breast Cancer: Hypofractionation with Simultaneous Integrated Boost vs. Standard Fractionation. Available from: www.clinicaltrials.gov/ct 2 / s how / NCT02474641.

47 Ditsch N, Kolberg-Liedtke C, Friedrich M, Jackisch C, Albert US, Banys-Paluchowski M, et al. AGO Recommendations for the Diagnosis and Treatment of Patients with Early Breast Cancer: Update 2021. Breast Care (Basel). 2021 Jun;16(3):214-27.

48 Krug D, Baumann R, Combs SE, Duma MN, Dunst J, Feyer P, et al.; Breast Cancer Expert Panel of the German Society of Radiation Oncology (DEGRO). Moderate hypofractionation remains the standard of care for whole-breast radiotherapy in breast cancer: considerations regarding FAST and FAST-Forward [et al]. Strahlenther Onkol. 2021 Apr;197(4):269-80.

49 Murray Brunt A, Haviland JS, Wheatley DA, Sydenham MA, Alhasso A, Bloomfield DJ, et al.; FAST-Forward Trial Management Group. Hypofractionated breast radiotherapy for 1 week versus 3 weeks (FAST-Forward): 5-year efficacy and late normal tissue effects results from a multicentre, non-inferiority, randomised, phase 3 trial. Lancet. 2020 May; 395(10237):1613-26. 
50 Machiels M, Weytjens R, Bauwens W, Vingerhoed W, Billiet C, Huget P, et al. Accelerated Adaptation of Ultrahypofractionated Radiation Therapy for Breast Cancer at the Time of the COVID-19 Pandemic. Clin Oncol (R Coll Radiol). 2021 Mar;33(3):e166-71.

51 Brouwers PJ, van Werkhoven E, Bartelink H, Fourquet A, Lemanski C, van Loon J, et al.; Young Boost Trial research group. Factors associated with patient-reported cosmetic outcome in the Young Boost Breast Trial. Radiother Oncol. 2016 Jul;120(1):107-13.
52 Poortmans PM, Collette L, Horiot JC, Van den Bogaert WF, Fourquet A, Kuten A, et al.; EORTC Radiation Oncology and Breast Cancer Groups. Impact of the boost dose of $10 \mathrm{~Gy}$ versus $26 \mathrm{~Gy}$ in patients with early stage breast cancer after a microscopically incomplete lumpectomy: 10-year results of the randomised EORTC boost trial. Radiother Oncol. 2009 Jan;90(1):80-5.

53 Immink JM, Putter H, Bartelink H, Cardoso JS, Cardoso MJ, van der Hulst-Vijgen $\mathrm{MH}$, et al. Long-term cosmetic changes after breastconserving treatment of patients with stage I-II breast cancer and included in the EORTC 'boost versus no boost' trial. Ann Oncol. 2012 Oct;23(10):2591-8.
54 EXamining PErsonalised Radiation Therapy for low-risk early breast cancer. A randomised phase III trial of adjuvant radiation therapy versus observation following breast conserving surgery and endocrine therapy in patients with molecularly characterised luminal A early breast cancer. Available from: www.breastcancertrials.org.au/current-clinical-trials/expert. 